\section{Los pasados cercanos: Reflexiones entre historia y memoria desde el Cono Sur}

The Past: Reflections between history and memory from the Southern Cone

\section{Romané Landaeta-SepúlVEdA*}

\section{Resumen}

El texto examina las relaciones entre Historia y Memoria, a través del análisis de la Historia del tiempo Presente, transiciones políticas a la democracia, la memoria histórica y el olvido. Para ello, analiza los enfoques teóricos metodológicos que han posibilitado reflexiones sobre los pasados recientes en América del Sur. Explora los debates en torno a las violencias políticas cometidas por los estados. Se centra en las problemáticas que comporta la memoria histórica de sociedades cuyo pasado reciente está vinculado con la sistemática violación de derechos humanos. Analiza el contexto latinoamericano problematizando en los

Grupo de Estudios Historia y Justicia, manelandaeta@gmail.com conceptos de memoria, historia y olvido a la luz de los procesos de transición política a la democracia.

Palabras clave: Historia, memoria, olvido, violencia política, transiciones a la democracia.

\begin{abstract}
The text examines the relations between History and Memory, through the analysis of the History of Present Time, political transitions to democracy, historical memory and oblivion. For this, it analyzes the theoretical methodological approaches that have made possible reflections on the recent past in South America. It explores debates around political violence committed by states. It focuses on the problems of the historical memory of societies whose recent past is linked to the systematic violation of human rights. It analyzes the Latin American context by problematizing concepts of memory, history and oblivion in the light of the processes of political transition to democracy.
\end{abstract}

Key words: History, memory, oblivion, Political violence, Transitions to democracy 


\section{Introducción}

La complejidad del pasado reciente en América Latina ha generado reflexiones en ámbitos que van desde la política pasando por la economía hasta aquellos aspectos socioculturales, problema-tizando las huellas que han dejado las violencias políticas de Estado en aquellas sociedades. Estas reflexiones también nos permiten acercarnos al entramado de las historias regionales en el que convergen diferentes zonas geográficas y culturales, compuestas a su vez de historias nacionales, donde conviven historias metropolitanas versus historias del margen; aquellas de la periferia que anidan historias mínimas, vinculadas más a lo cotidiano, a aquello que en general tienden a olvidar las grandes historias, pero que movilizan la suma de nuestros días.

Me interesa examinar nuestros pasados cercanos que se han organizado en ciertos marcos sociales de memoria ${ }^{1}$, nutridos de historias vitales heredadas de historias familiares, que a su vez son parte de historias locales (rurales y urbanas), nacionales y regionales. Es decir, es una reflexión que va de lo general a lo particular, colocando el acento en aquellas complejidades que han ido hilvanando el tiempo presente Latinoamericano. En efecto, si examinamos desde una panorámica general las problemáticas que se observan sobre todo en la segunda mitad del siglo XX, es posible advertir las dificultades que se advierten en sociedades que han experimentado situaciones traumáticas, sobre todo debido a la violencia ejercida por el Estado, en donde se cometieron de forma sistemática violaciones a los derechos humanos.

En el sentido que propone Halbwachs, M.2004. Los Marcos sociales de la memoria. Barcelona: Anthropos.
Lo que propongo para situar el análisis, es considerar tres focos de reflexión definidos que permiten examinar las dificultades que se advierten en la región, cuando se analizan los pasados cercanos cuyo elemento transversal fue la violencia sistemática.

El primero de ellos, está relacionado con el análisis de la historia del tiempo presente, que a través de la memoria histórica como fuente, se accede al examen del pasado del que somos coetáneos, apreciando las diversas formas y narraciones que éste adquiere.

Un segundo eje, viene dado por el examen de las transiciones políticas a la democracia a escala general, donde es posible identificar procesos de toma de decisiones en el actual sistema globalizado, y en el que se aprecian los diferentes mecanismos adoptados por los gobiernos, cuyos esfuerzos han estado más orientados en promover y mantener equilibrios, por ejemplo, en materia política y social, que en una justicia real; desafío no menor en sociedades cuyas prácticas estatales y burocráticas permitieron la sistemática violación de derechos humanos (cometidas por regímenes dictatoriales).

Un último ámbito de análisis, es aquel que se relaciona con el análisis de las huellas dejadas por esas violencias, examinando la memoria y olvido de esos pasados recientes. Estos ámbitos de análisis permiten ingresar -insisto desde panorámicas generales-, entre otros, al tema de los derechos humanos, que abarca por cierto, un importante campo de reflexión, y que ha sido fundamental tanto en la implementación como profundización de los procesos de democratización en diversas regiones del mundo, y donde América Latina no ha estado ajena. 
Como sabemos, esto se debe fundamentalmente a que luego de experimentar la violencia de Estado las sociedades del posconflicto o postdictadura, a través de sus gobiernos transicionales debieron afrontar y responder ante las herencias dejadas por los regímenes dictatoriales, cuya constatación de los hechos históricos fue inequívoca: Las miles de víctimas, entre ellas, muertos, detenidos desaparecidos, ejecutados políticos, junto a quienes lograron sobrevivir a los padecimientos cometidos. Esa es la mayor impronta del pasado reciente de estas sociedades. En definitiva, una de las tareas prioritarias de los gobiernos transicionales ha sido el restablecimiento de la democracia y sus instituciones, generando las condiciones para la existencia de un real Estado de derecho, implementando a su vez una red político-estatal que promoviera el respeto absoluto de los derechos humanos.

Estos asuntos adquieren gran relevancia en las dinámicas sociales de nuestro tiempo, donde los aspectos históricos, antropológicos, culturales e internacionales, influyen y hasta cierto punto determinan las formas en que cada sociedad ha intentado hacer frente a estos temas. Pero al mismo tiempo, estas problemáticas, nos permiten indagar en las formas en que es posible historizar el pasado reciente de sociedades que como la nuestra, ha tenido altas cotas de complejidad asociadas a la violencia ejercida por el Estado, o bien que se han cometido dentro de él. Asimismo, es posible reflexionar sobre las formas en que los gobiernos han hecho frente a los legados del pasado represivo, examinando la memoria histórica que este tipo de sociedades ha elaborado sobre su pasado represivo.

Todos estos temas adquieren la mayor relevancia al constatar las narraciones e interpretaciones que se generan sobre un mismo hecho, esto es, la violencia ejercida; es aquí donde se hace necesario elaborar trabajos de memoria, como lo ha señalado la socióloga Elizabeth Jelin (Jelin 2002) permitiendo examinar esos pasados cercanos a luz del análisis de la memoria histórica como fuente, visibilizando entre otros, los lugares de memoria -en el sentido propuesto por Pierre Nora (Nora1992), resignificando espacios donde se cometieron las acciones de violencia, transformándolos en lugares de memoria, que se instalan no sólo para combatir el olvido sino también para proyectarse en una acción de futuro hacia los Nunca Más. En estos 'esfuerzos de memoria', convergen la heterogeneidad de debates, así como las tensiones y acuerdos presentes en las diferentes sociedades en torno al uso, reapropiación y destino de los lugares donde se perpetraron las violencias. Relación que por cierto se instala en la dinámica histórica, es decir, desde el presente analizar el pasado para proyectarse hacia el futuro.

En consecuencia las 'huellas' del pasado represivo quedarían incompletas sin el relato de las víctimas que han sobrevivido, y las historias de vida de quienes desaparecieron o perdieron la vida. Es decir, la representación de esa ausencia-presencia, queda en un vacío, que cobra sentido cuando se trae desde el pasado el proyecto político que se intentó destruir, cuyos rastros y rostros de la violencia ejercida con la impunidad del fusil, se manifiesta en los relatos cotidianos, que son parte de nuestro acontecer histórico.

En efecto, en la comprensión de estos pasados, la contribución de una mirada arqueológica en el sentido propuesto por Michel Foucault (Foucault 1986)- resulta oportuna, ya que nos 
aproxima al reconocimiento de las formas en que se ha construido la arquitectura del horror vivido, reconociendo como capas superpuestas las formas en que se materializaron esos padecimientos, cuyos contenidos fueron entre otros, la reclusión fuera de toda legalidad, tortura, muerte y desaparición de las víctimas, que unidos al miedo, impotencia, dolor, indefensión, frío, hambre, abyección y tristeza, nos acercan a esas profundas mixturas que comporta el dolor, cuya experiencia "es sensorial y emocional" (Le Breton 1999: 10) . En consecuencia, es indudable que los problemas asociados a la narración y elaboración desde el presente de este tipo de pasados, no son fáciles, debido a las heridas, deudas e injusticias que contiene.

\section{Sobre los pasados recientes: Aproximaciones a la Historia del Tiempo Presente}

Las prácticas cometidas por las violencias de Estado sin duda han dejado profundas huellas y fracturas. Estas experiencias traumáticas que visibilizan mayormente a partir de la segunda mitad del siglo $\mathrm{XX}$, tienen como resultados pasados mediatos complejos de abordar, no sólo por sus catastróficas consecuencias, sino también porque generan revisionismos que en algunos casos los favorecen, o bien cuestionan, llegando incluso a negar los hechos ocurridos².

Son estos y otros problemas los que llevan a replantear dentro de la comunidad histórica los objetivos, métodos y archivos con que

Un ejemplo clásico son los historiadores negacionistas del Holocausto judío como David Irving en Gran Bretaña, David Duke y Arthur Butz en Estados Unidos, Robert Faurisson en Francia, Ernst Zündel en Canadá. Véase Vidal- Naquet, P. 1994. Los asesinos de la memoria, México D. F., Siglo XXI. usualmente trabajamos. Es en medio de estas complejidades que, desde nuestro oficio, se observa un profundo debate orientado en tratar los temas vinculados a los pasados recientes.

Considerando estas complejidades, el historiador Julio Aróstegui se interrogaba sobre estas cuestiones, "¿cómo podría y, en consecuencia, cómo debería el/a historiador/a acercarse a las realidades sociales presentes?" (Aróstegui 1998: 31), puesto que los problemas y preguntas están en constante replanteamiento, esta es una de las cuestiones que comporta una mayor dificultad, esto es, ¿cómo definimos el presente?, cuestión que se refiere específicamente a la noción de tiempo histórico. El historiador François Bédarida, señala la necesidad de detenernos en la precisión de estos temas:

El lugar de la temporalidad extendida que contiene la memoria de las cosas pasadas y la expectativa de las cosas por venir. 'El presente del pasado es la memoria; el presente del presente es la visión; el presente del futuro es la expectativa' (Bédarida 1998: 22).

Coincidimos con estos autores respecto a que el problema del movimiento pendular del presente, no es en estricto rigor la demarcación que puede existir hacia atrás, sino que la dificultad está hacia adelante, ya que las fronteras no son claras, siendo más bien un terreno movedizo. Por ello François Bédarida insiste en llamar "tiempo presente, el tiempo de la experiencia vivida" (Bédarida 1998: 22). En ello concuerda también la historiadora Anne Pérotin-Dumon, señalando que:

Es poner el acento en la relación de contemporaneidad que la proximidad del pasado introduce entre el historiador o la historiadora y su objeto: es 'historizar la experiencia propia', se escribe 'la historia del mundo en que vivimos' (Pérotin-Dumon 2007:17). 
En esta misma línea, otra de las inquietudes que se aprecian al considerar estas problemáticas y enfoque histórico, es el que se relaciona con la noción de 'acontecimiento' que adquiere una vital relevancia, ya que "Feliz o trágico, colectivo o individual, público o privado, un acontecimiento es, pues, lo que se distingue de la trama normal de los trabajos y los días" (Trebitsch 1998: 30).

Estas cuestiones cobran vital importancia a propósito de las fechas 'in-felices', y las conmemoraciones que cada año se realizan en diversas regiones del mundo. Estas preocupaciones emergen debido a la inquietud que ofrecen las cercanías de los hechos, la proximidad de los relatos y aquella 'subjetividad' que obligaba a tomar distancia, exigiendo investigaciones donde la asepsia y rigurosidad científica decimonónica eran una condición sine qua non en las elaboraciones teóricas y metodológicas delas Humanidades y las Ciencias Sociales. Por ello, al analizar estas cuestiones es imperativo comprender la temporalidad que comportan estas problemáticas. Es fundamental salir de nuestros despachos y estar en la comunidad, como señalaba Marc Bloch; las/os historiadoras/as debemos estar donde está el mundo (Bloch 2001). Desde esta perspectiva, la Historia del Tiempo Presente tiene una connotación más profunda en cuanto a su campo investigativo, esto es, porque trata 'nuestro tiempo' (Aróstegui 2004).

En efecto, la historiadora Graciela luorno sostiene que: "El estudio de la historia presente implica considerar el factor de cambio cultural y político, teniendo en cuenta que es la historia de la cultura de nuestro tiempo" (luorno 2010: 42). Esta multitud de equivalencias respecto al concepto, plantea también debates centrados sobre todo en el recuerdo, o re-elaboración de ciertos acontecimientos, o fechas episódicas. Mi interés, es poner de manifiesto los debates existentes que tienen como telón de fondo el hacer frente a pasados que encuentran sus 'puntos nodales' en las herencias que dejaron las violencias sistemáticas, y que abarcaron no sólo los ámbitos jurídicos, sociales y culturales, sino que también constituyen temas pendientes en la región. Puesto de que como expresaba Marc Bloch, "por mucho que el pasado no determine totalmente el presente, sin aquel, este permanece ininteligible" (Bloch 2001: 150.151). En definitiva, como señala Julio Aróstegui:

\begin{abstract}
(...) la historia de lo 'presente' es una historia en buena parte distinta de las ya conocidas, pero también es claro que es 'historia' y no otra cosa, aunque sus relaciones con otras investigaciones sociales deban ser más estrechas todavía que en otros sectores historiográficos. Hacer del presente una historia plena, historizar el presente, requiere repensar la historiografía con rigor, lejos de convencionalismos (Aróstegui1998: 41).
\end{abstract}

Por esta razón resulta de suma importancia indagar sobre estos temas, que sin duda son difíciles de abordar, porque tratan sobre 'nuestro tiempo' y del cual somos 'testigos', pero también porque están vinculados a fracturas que han experimentado nuestras sociedades, y donde los gobiernos de turno han tomado diversas formas de abordar estos pasados. No obstante, estas preocupaciones desde y hacia nuestro quehacer disciplinario traspasan las geografías, observando similitudes y diferencias que se advierten al analizar este tipo de sociedades, se advierte como señala la cientista política Alexandra Barahona que:

(...) una de las cuestiones políticas y éticas más importantes con que se enfrentan las sociedades durante la transición de un gobierno autoritario o totalitario a otro democrático es cómo hacer frente al legado de un pasado represivo. Éste es a menudo el problema con un mayor 
potencial para desestabilizar el proceso de transición (Barahona, Aguilar y González 2002: 29).

Advertimos que, en estos casos, la necesidad de consensos y acuerdos de la sociedad en su conjunto, presenta grandes paradojas.

\section{Transiciones políticas a la democracia. Análisis en perspectiva histórica}

Las investigaciones que se refieren a las sociedades que han experimentado la violencia política, remite como espacio histórico de análisis a los procesos de cambio político, esto es, al estudio de las transiciones, ya que no existen casos de recuperación de memoria histórica sobre estos pasados en dictadura, puesto que ello significaría una contradicción en cuanto a la naturaleza de su concepto. Asimismo, las consecuencias que han dejado esas situaciones traumáticas, se advierten con mayor claridad en los procesos democráticos. Es fundamental conocer los mecanismos a través de los cuales estas sociedades transitaron hacia la democracia, y más aún, la forma en que irrumpieron las memorias de esos pasados violentos, y cuáles fueron los tipos de memorias que emergieron.

El estudio de las transiciones políticas, ha generado en las últimas décadas importantes investigaciones que otorgan luces al problema de aquellas sociedades que han tenido regímenes autoritarios y pasados dictatoriales. Las experiencias analizadas dan cuenta de la complejidad de los procesos, las tensiones y debates que se suscitan por parte del conjunto de la población sobre dos cuestiones centrales; de un lado, qué hacer con ese pasado 'difícil' que abarca una gran cantidad de parcelas de la sociedad, y de otro, cómo organizar la futura democracia. Es decir, cómo las sociedades que han experimentado la represión política por parte de sus Estados, establecen los criterios de lo que debe contener el Estado de Derecho.

Las investigaciones han permitido complejizar las problemáticas, superando aquellos debates cuya preocupación central estaba orientada más en la precisión del concepto que en el examen de los procesos. A pesar de ello, se advierte una correspondencia en la comunidad científica al entender a las transiciones políticas, como "el intervalo entre un régimen político y otro" (O'Donnell y Schmitter 1988: 19), considerando la diversidad y particularidad de cada realidad histórica. A este respecto, Álvaro Soto señala:

\footnotetext{
Lo realmente importante para los investigadores es describir y analizar cómo durante las transiciones, y debido a su naturaleza política, convivieron al mismo tiempo actitudes e instituciones autoritarias con otras democráticas; cómo se procedió a desmontar el Estado con Derecho para poder así construir el Estado de Derecho (Soto 2009: 11).
}

Los mecanismos que utilizaron las sociedades para afrontar este tipo de problemáticas fueron diversos, respondiendo en muchos casos a las realidades históricas, sociales y culturales de que eran herederas. De la misma forma, se advierte la emergencia de demandas tanto de la sociedad civil como de instituciones vinculadas a temas de derechos humanos, que durante los años de represión acogieron a cientos de personas, resguardando la vida de los perseguidos y procurando la libertad de los detenidos. Aunque no se debe olvidar "que parte de la transición se produce en un marco político donde el peso de la 'situación' autoritaria era elevado" (Soto 2009: 12), lo que se traduce en el miedo justificado hacia la policía y los militares. Sin embargo, la búsqueda de la verdad de los hechos ocurridos, así como la exigencia de justicia frente a los 
delitos cometidos, se transformaron en los mayores petitorios reclamados por parte de las fracturadas sociedades. En consecuencia, la forma en que se resolvieron los problemas que ocasionaron los regímenes dictatoriales, tuvieron algunas similitudes que se aprecian con mayor profusión en los casos del Cono sur de América.

\begin{abstract}
Las sociedades en transición afrontan los legados de represión por medio de amnistías, juicios o purgas, establecimiento de Comisiones de Verdad, compensación financiera y gestos simbólicos como la construcción de monumentos o la proclamación de días conmemorativos (Barahona, Aguilar y González 2002: 29).
\end{abstract}

En la investigación citada, señala que las políticas de verdad y justicia que se desarrolla en cada país, dependen del tipo de transición que construyen. Indican que cuanto más vencida y disminuida llega la élite del régimen anterior a la transición, existen mayores posibilidades para incorporar este tipo de políticas. Los procesos transicionales son mucho más complejos que un simple cambio de gobierno o un proceso de liberalización, ya que inciden cuestiones que están relacionadas con acuerdos y disputas entre las élites políticas que provienen del período autoritario y la oposición a este.

De acuerdo al ámbito de acción, es posible encontrar transiciones por ruptura, que pueden tener lugar después de una intervención extranjera y dar una victoria total a las fuerzas ocupantes. En este caso corresponde lo sucedido en Europa y Japón, luego de la Segunda Guerra Mundial. Asimismo, como señala el estudio citado, esta ruptura también se puede dar luego de una guerra revolucionaria o civil, que conduce a la derrota militar de las fuerzas dictatoriales. Esta es la situación de países de América Central como Nicaragua en 1979. Y de América del Sur, como en Bolivia que luego del régimen de García Meza, "ofrece un ejemplo de ruptura y caída tras la movilización masiva y un golpe militar contra la facción de las Fuerzas Armadas que apoyaba a ese gobierno" (Barahona, Aguilar y González 2002: 41-42).

Otra forma de transición por ruptura, "tiene lugar cuando el régimen cae debido a un desgaste gradual de la legitimidad interna y de la pérdida de control del poder y/o de recursos ideológicos clave" (Barahona, Aguilar y González 2002: 42). Esto puede ocurrir luego de la derrota en una guerra exterior, como sucedió en el caso de Argentina en 1983, luego de la guerra de las Malvinas, o bien en el fracaso de Grecia en la guerra de Chipre en 1975. Este quiebre, también puede ser provocado por una acción revolucionaria protagonizada por fuerzas militares. Las autoras colocan como ejemplo el caso de Portugal, luego de la prolongada participación en las guerras coloniales de Mozambique, Angola y Guinea Bissau. De igual forma, este tipo de crisis, se puede evidenciar cuando se desencadena el hundimiento económico e ideológico, así como el derrumbe de los referentes internacionales como fue en Europa del Este y Rusia.

En otro extremo, se sitúan las transiciones negociadas, también denominadas pactadas, que se orientaron más a las reformas que a la ruptura.

\footnotetext{
En estos casos, las autoridades de los regímenes represores salientes, suelen conservar tal magnitud de poder que la nueva elite democratizadora tiene que coexistir y negociar constantemente el cambio con la vieja guardia (Barahona, Aguilar y González 2002: 42).
}

Aquí se encuentran los casos de España, gran parte de los países de América Latina y Central y Suráfrica. En este tipo de transiciones existe una idea de 'equilibrio de poder', como lo denominan las autoras, pero que en los ámbitos de acción, sobre todo en lo referido a los derechos humanos, es muy limitado. En 
este aspecto señalan por ejemplo, que en casos como los referidos a las transiciones ocurridas en Europa del Este, resultan especiales debido a que "tuvieron lugar en un contexto de crisis ideológica, cambio social y económico, que privaron a la élite comunista de los recursos de poder preexistentes" (Barahona, Aguilar y González 2002: 43), debido al profundo cambio que experimentaron estas sociedades. Además indican que en estos procesos, un elemento central que permite observar cómo se desarrollan los procesos transicionales, está relacionado en cómo se articulan los diversos grupos políticos dentro de la sociedad.

\footnotetext{
La negociación entre estos grupos políticos y su fuerza relativa en los procesos de transición constituyen una variable fundamental para el entendimiento de cuándo y cómo se crean Comisiones de Verdad y se adoptan medidas de justicia retrospectiva, como purgas y enjuiciamientos (Barahona, Aguilar y González 2002: 44).
}

Agregan que existen otros elementos que condicionan la búsqueda de la verdad y justicia en estos procesos, además de las propias limitaciones y oportunidades que puedan existir. Entre ellos, es posible identificar las actitudes y creencias de los nuevos dirigentes y partidos políticos, así como las leyes y los marcos institucionales. También influye la naturaleza del liderazgo, sobre todo en países con sistemas presidencialistas, junto a las características de las fuerzas de oposición al régimen dictatorial, puesto que esto también repercute en las estrategias para enfrentarse con el pasado y el tipo de políticas adoptadas.

En definitiva, cada proceso histórico tiene su propio ideario, en el que es posible identificar una diversidad de experiencias nacionales. En este caso, las transiciones políticas junto a la implementación de formas democráticas de conducción estatal, también deben abordar otros temas como la recuperación de espacios democráticos y plurales, fomentar la reflexión sobre su pasado cercano, es decir, la interpretación histórica de los hechos, facilitar la información vinculada a los sucesos ocurridos, generando una mayor compresión en la sociedad civil sobre el pasado represivo. A ello se suman, las posibles soluciones que puedan responder a las demandas de verdad y justicia, y que entran en tensión cuando se utilizan en afirmaciones referidas al pasado de una sociedad, donde se hace necesario considerar que ninguna versión única de la verdad puede excluir a las demás posibles.

\footnotetext{
En Chile, por ejemplo, rivalizan al menos dos explicaciones sobre las graves violaciones de los derechos humanos cometidas por la dictadura de Pinochet (algo que ya nadie niega). Ambas pueden satisfacer las normas habituales de verificación de diversos criterios de verdad, pero reparten responsabilidades en direcciones contrapuestas $y$, por tanto, tienen implicancias enfrentadas sobre el ámbito de la 'justicia' (Whitehead 2002: 29).
}

Por consiguiente, la llamada 'justicia transicional' centra sus políticas públicas en un tiempo delimitado y con objetivos definidos, como "el reconocimiento oficial de los abusos o del sufrimiento de las víctimas. Estos dos procedimientos que son a la vez discursivos y catárticos" (Whitehead 2002: 29). Algunos autores señalan que esto permite realizar un ejercicio terapéutico en la sociedad, facilitando la manifestación de los traumas sociales, ofreciendo un cierto grado de seguridad en el futuro, ampliando las áreas de la justicia punitiva. Es decir, exigiendo el castigo a los culpables, y reclamando la compensación para las víctimas. No obstante, este tipo de medidas no son fáciles, debido al gran entramado de debates, tensiones y actores políticos implicados, y que influyen en el tipo de políticas adoptadas por los Estados para abordar estos temas. En algunos casos se llega 
incluso a considerar que, no es oportuno castigar a los que cometieron injusticias hace mucho tiempo, y en un contexto muy diferente, situación que se torna difícil por la falta de pruebas o bien, porque los supuestos victimarios han fallecido. Un caso emblemático es lo sucedido en España, por cuanto uno de los grandes pactos dentro la elaboración de su proceso transicional, fue el acuerdo de silencio respecto a las violaciones de derechos humanos cometidas durante los cuarenta años de la dictadura franquista, debido al recuerdo de la Guerra Civil ${ }^{3}$.

La decisión adoptada por parte del Estado de dar a conocer de forma pública, tanto los delitos cometidos como sus responsables, pone de manifiesto el interés por defender y construir una sociedad con mayor justicia. Por consiguiente, se observa que son las jóvenes democracias quienes deben hacer frente a sus pasados represivos, tomando decisiones que pueden ir desde el establecimiento de 'silencios comunicativos', o bien del respaldo a peticiones generadas por parte de la sociedad civil para sacar de cargos públicos a responsables y cómplices de los regímenes dictatoriales. Estas acciones provocan que, en determinados casos, la búsqueda de la verdad sobre los hechos ocurridos, lleve a mejorar la confianza en la justicia. Aunque con independencia de la decisión que se tome, usualmente tienden a quedar pendientes las demandas.

En consecuencia, la eventual solución depende fundamentalmente de la voluntad política con

Aunque la institucionalización del consenso, fue la consecuencia más destacada de la transición española, no es menos cierto, que la memoria histórica sobre estos pasados, genera tensión en la sociedad, sobre todo, porque aún está pendiente el reconocimiento oficial de las víctimas de la Guerra Civil y la dictadura franquista. Véase Paloma Aguilar. 2002. Políticas de la Memoria y Memorias de la Política. Madrid: Alianza Editorial. que se quiera responder, cuestión que resulta esencial para evitar que este tipo de asuntos queden pendientes y dificulten el futuro de las recuperadas democracias. Un caso representativo de este tipo de problemas que han quedado irresueltos es el de Francia, respecto a su responsabilidad frente a la guerra de Argelia. Estos asuntos nos llevan a reflexionar, respecto a la importancia del pasado, puesto que no se puede evadir, ni menos aún negar, ya que se manifiesta de diversas formas, evidenciando las huellas y deudas de esa situación traumática, no importando el tiempo transcurrido. Es decir, en el momento en que esos pasados 'irrumpen', es cuando mayores posibilidades existen de volver la mirada atrás y reflexionar sobre ellos. En el caso de sociedades que contienen este tipo de pasados, estos 'brotes' de memoria, generan tensiones frente a la eficacia de la justicia y la propia política, debido a que en el ejercicio de introspección que realiza la propia sociedad civil lo que se busca, es intentar comprender, entre otros, los elementos que llevaron a que se desatara la violencia política.

La diferenciación sobre los tipos de transiciones permite apreciar, por un lado, los matices que existen en cada experiencia histórica, donde influyen tanto las trayectorias políticas como las características socioculturales. Por otra parte, se observa que aun cuando presentan diferencias en sus procesos históricos, poseen elementos comunes, entre los que se pueden mencionar la experiencia de violencia, junto a la forma en que abordaron las transiciones y sus legados represivos. Asimismo, en algunas de estas sociedades, es posible detectar cierto interés por parte del Estado, y de determinadas entidades gubernamentales de buscar mecanismos que permitieran algún grado de reconciliación con ese pasado. Entre ellos, 
se encuentran los esfuerzos de las diversas "comisiones de investigación, purgas, juicios y amnistías" (Whitehead 2002: 30).

Del mismo modo, se percibe una amplia gama de iniciativas que han emergido desde la sociedad civil y que también han intentado hacer frente a esos pasados. No obstante, posible identificar cierto grado de pasividad en la sociedad civil, situación que se manifiesta en la negación de los hechos, estableciendo responsabilidades de forma equitativa, sobre todo frente al tema de las víctimas. Lo que lleva a restarle importancia a la violencia ejercida, más aun, rehusándose a hacer memoria. Sin embargo, es posible constatar que a pesar de ello, ha existido una gran movilización social promovida sobre todo por organizaciones no gubernamentales, vinculadas a la defensa de los derechos humanos, entre las que destacaron las iglesias, así como partidos políticos de izquierda, y diversas organizaciones sociales, entre las que destacan las Madres de la Plaza de Mayo en Argentina, y la Vicaría de la Solidaridad en Chile ${ }^{4}$.

Estas organizaciones realizaron muchas veces de forma clandestina, acciones de denuncia sobre los hechos que estaban ocurriendo, y que se pueden identificar con las acciones que en el ámbito académico se denominaron 'políticas de la memoria', ya que tienen directa relación con la forma en que las sociedades representan y narran sus pasados ${ }^{5}$.

Véase <http://www.archivovicaria.cl/>. (Consultado en octubre de 2016)

Algunas de ellas fueron, la Agrupación de Familiares de Detenidos Desaparecidos (AFDD), que comenzó a funcionar a fines de 1974. Fundación de Ayuda Social de las Iglesias Cristianas (FASIC), se creó el 01 de abril de 1975.Corporación de Promoción y Defensa de los Derechos del Pueblo (CODEPU), fundada el 8 de noviembre del año 1980.El Centro de Salud Mental y Derechos Humanos (CINTRAS), creado en 1985.El Instituto de Salud Mental y Derechos Humanos (ILAS), creado en 1988.
Este tipo de prácticas, tuvieron una importante repercusión no sólo en el conjunto de la sociedad, sino también en la propia forma en cómo se articuló la política en las jóvenes democracias, ya que es durante los procesos transicionales donde se desarrollan las mayores iniciativas tendientes a promover los trabajos de memoria. En este contexto, coincidimos con la socióloga Elizabeth Jelin, respecto a que el ejercicio de memoria, comporta un aspecto más íntimo, que se relaciona con las experiencias particulares, sea a nivel personal o grupal. Por tanto, el desafío se debe trasladar a lo colectivo, esto es, permitir que sea la sociedad civil en su conjunto quien desarrolle estas labores. Para lograr este objetivo, es necesario que el Estado proporcione herramientas, mediante una política estatal que fomente la recuperación de la memoria, para lograr una sociedad más justa y equitativa, donde la gobernanza junto a la cohesión social, sean los objetivos a alcanzar.

Los análisis que se han realizado sobre los procesos democratizadores y las transiciones políticas, presentan una abundante literatura. Entre ellos, uno de los estudios de mayor difusión, dentro de este tipo de investigaciones es el realizado por Samuel Huntington, quien analiza la expansión de la democracia contemporánea como producto de 'olas' de democratización, seguidas de 'contra-olas' autoritarias. Sitúa la primera de ellas, entre 1828 y 1926, con la instauración de las democracias liberales en Estados Unidos e Inglaterra, para luego extenderse por el resto de Europa. Posteriormente, según su análisis, habría seguido una contra-ola, entre los años 1922 y 1942, cuyo hito fue la marcha de Mussolini sobre Roma, y que correspondió al fascismo del período llamado de entreguerras. La segunda ola, se habría iniciado con la victoria 
de los aliados sobre las potencias del eje en la Segunda Guerra Mundial. A este proceso, le siguió una segunda 'contra-ola' entre 1958 y 1975 caracterizada por el militarismo, las revoluciones, y contrarrevoluciones golpistas, que afectaron sobre todo a la región de América Latina. En último lugar, según el planteamiento de Huntington, habría existido una tercera 'ola' democratizadora, caracterizada por la expansión de los procesos transicionales iniciada "de manera poco convincente e involuntaria, veinticinco minutos después de la medianoche, del martes 25 de abril de 1974, en Lisboa, Portugal" (Huntington 1994: 75), abarcando el sur de Europa, América Latina, y luego Europa del Este.

"Para Huntington el cambio de más de treinta países desde el autoritarismo a la democracia constituyó el más importante desarrollo global" (Jiménez 2009: 13). Aun cuando esta periodización es aceptada en términos generales por la comunidad científica, existen algunas precisiones de especialistas, provenientes tanto de la historia como de las ciencias sociales. Si bien exceden el propósito del texto, nos interesa al menos enunciarlos, ya que permiten tener mayor claridad frente a cada proceso. Para Enrique Gil Calvo, esta 'ola' se habría 'quebrado' con las protestas de la Plaza de Tiananmen de 1989, y el conflicto en los Balcanes. Por otra parte, Juan Carlos Jiménez señala que:

\footnotetext{
El problema del concepto de «tercera ola» es que incluye procesos tan diferentes que, más allá de ciertas generalizaciones demasiado vagas, difícilmente puede generar un modelo explicativo válido que sirva como guía de democratización (Jiménez 2009: 13).
}

Sin embargo, admite que la propuesta de Huntington permite adentrarse en dos elementos que a su juicio son relevantes en los procesos de democratización. El primero, tiene relación con la idea de que estos procesos no se dan de manera individual en una región, sino que usualmente tienen sincronías, que alcanzan gran relevancia debido a las propias características de las experiencias históricas de las sociedades:

(...) en los que existen factores de interdependencia explícitos, ya sea de tipo geoestratégico, económico, social, político, o de carácter implícito, entendiendo por tales elementos de tipo cultural o de mentalidades (Jiménez 2009: 13).

El segundo elemento relevante en el análisis que propone Jiménez, está relacionado con la idea de democracia, "concebida como un proceso histórico de desarrollo político que lleva de la autocracia a una democracia de tipo y en esencia liberal" (Jiménez 2009: 14), sobre la base de un marco político respetuoso de los derechos fundamentales. Subraya que, si bien la democracia admite diversas fórmulas, la importancia radica en que se produce cuando el gobierno se basa en un principio de legitimidad.

Asimismo, Alexandra Barahona, sostiene que una de las características del siglo XX, fue la búsqueda de la justicia política, cuestión que se observa con mayor profusión en los procesos de transición a la democracia. Señala a su vez, que el rasgo distintivo de la pasada centuria fue el genocidio y los crímenes de lesa humanidad, junto a la "invención de nuevas formas de respuesta legal [es] y distintivas a dichos acontecimientos" (Barahona 2002: 31), donde los juicios de Núremberg (1945-1946) sentaron las bases de la jurisprudencia en materia de crímenes contra la humanidad.

Examina los grandes ciclos de institucionalización de la democracia representativa, coinci- 
diendo con las etapas señaladas por Huntington. Si bien examina los procesos transicionales en las diferentes regiones, su atención se focaliza en las políticas de reparación adoptadas por los diferentes Estados. Señala que, en el transcurso del siglo XX en Europa, han existido 'tres olas de verdad y justicia', que coexisten con las etapas de democratización desarrolladas en la región. Es decir, para una misma parcela de tiempo, y frente a las experiencias de regímenes dictatoriales, se observan dos análisis que resultan fundamentales. De un lado, el desarrollado por Samuel Huntington, que se refiere a las olas democratizadoras, y de otro, el de Alexandra Barahona que examina las políticas de verdad y justicia.

Dentro de las etapas de verdad y justicia, la primera se puede situar luego de la Segunda Guerra Mundial, y que corresponde a la segunda ola democratizadora en el esquema de Huntington. Esta fase es considerada como predecesora de las modernas iniciativas de justicia en la transición cuyo centro fue el Tribunal Militar Internacional de Núremberg, junto a los juicios nacionales, que se efectuaron tanto en Alemania como en países que habían sido invadidos. Es decir, las primeras políticas tuvieron como propósito tomar medidas luego de los gravísimos daños dejados por la guerra, y la implantación de los sistemas totalitarios.

La segunda etapa de políticas de verdad y justicia durante el proceso de transición, tuvo lugar en el sur de Europa, en Grecia, Portugal y España. Se observa que cada país promovió diferentes políticas para oponerse a las cúpulas de represión y autoritarismo del pasado. En el caso de Grecia, se realizaron entre 1974 y 1975, juicios que "sentenciaron a 24 de los más de 100 hombres que habían dirigido el golpe de 1967" (Barahona 2002: 32). Asimismo, un alto número de funcionarios fueron depuestos de sus actividades, y se abrieron cientos de procesos por tortura, aunque se dictaron pocas sentencias. La revolución de los claveles en Portugal (1974), puso fin a una de las dictaduras más extensas de Europa, (1926-1974). Esta experiencia significó que en los primeros años del proceso de transición se realizaran amplias purgas, quedando momentáneamente el poder político en manos de las fuerzas revolucionarias de izquierda y militares radicales. Como en otros casos que se desarrollarían más tarde, se destituyeron de sus cargos a los dirigentes de la antigua administración de la dictadura de António de Oliveira Salazar ${ }^{6}$. En el caso de España, se "optó en 1977 por la amnistía y por un 'olvido' casi institucionalizado por lo que respecta a la Guerra Civil y a la dictadura de Franco" (Barahona 2002: 32). Como lo expone Paloma Aguilar, el miedo a esta memoria traumática llevó a que se optara durante la transición por la política del consenso.

El miedo a una vuelta a la violencia política y la culpa compartida por los abusos cometidos durante la Guerra Civil, llevaron a la elite de la transición y a la mayor parte de la sociedad civil a aceptar e incluso a preferir una amnistía general (Barahona 2002: 48).

Lo que se advierte en este caso, es que más allá de examinar las causas que desencadenaron el conflicto, así como identificar a los responsables de las atrocidades cometidas, y los elementos que llevaron al clima de extrema violencia como fue la Guerra Civil y la dictadura franquista. Al parecer, lo que generó mayor preocupación fue evitar repetir esas experiencias, es decir, luchar

De Sousa Dias, Susana, 48, Lisboa, Betacan Digital. PAL., 2009. Es un excelente documental, su nombre hace referencia a los años de la dictadura en Portugal. 
por la consecución de un Nunca Más, lo que también implicó pactos, renuncias, cesiones y compromisos por parte de la sociedad española en su conjunto.

Por último, una tercera etapa que se advierte en las políticas de verdad y justicia, es la que se inició en América Latina a mediados de la década de 1980, para luego extenderse por Europa del Este, llegando a África y Asia en el período de 1990. Es durante los procesos de transición política en el Cono Sur, cuando se realizan las investigaciones sobre violaciones de derechos humanos cometidas en los regímenes anteriores, y que más tarde se extendieron por América Central a través de procesos de paz. Es interesante apreciar dentro de esta región las tensiones y conflictos que suscitaron este tipo de investigaciones, que a diferencia del caso español, la cercanía de los hechos ha generado un gran desafío para estas heterogéneas sociedades.

\subsection{Transiciones políticas y las Comisiones de Verdad en América Latina}

En el caso de América Latina, se advierte que los procesos de transiciones políticas se enmarcaron en un ciclo, en el que convertiría a la democracia electoral en la norma de la región, y no en su excepción. En efecto, podemos situar el inicio de estos procesos a partir de las elecciones de 1978 en Ecuador, cuando se restituyó el gobierno democrático, convirtiéndose en la primera experiencia en el continente, en que los militares dejaron del poder. Luego continuarían Perú en 1980, Bolivia en 1982, Argentina en 1983, Brasil y Uruguay en 1985, Paraguay en 1989, y Chile en 1990. Y en cuyos procesos se originaron las llamadas Comisiones de Verdad.
Argentina (1984) y Chile (1990) establecieron oficialmente comisiones que emitieron informes sobre la represión. En Bolivia (1982-1983), Uruguay (1985) y Paraguay (1992) la tarea recayó en comisiones parlamentarias. También organizaciones no gubernamentales (ONGs) emprendieron investigaciones en Brasil (1979-1985), así como en Paraguay (1984-1990) y Bolivia (1990-1993); cada una de ellas elaboró informes no oficiales sobre la violencia política (Barahona 2002: 33).

En Argentina, la derrota experimentada en el conflicto de las Malvinas, también implicó para la transición política un momento interesante, por cuanto, si bien la salida de los militares fue inminente, ésta se caracterizó por el abatimiento producto de la derrota militar. Esta situación posibilitó que las primeras políticas de verdad y justicia tuvieran la fuerza e importancia suscitada en los primeros años del proceso transicional. Luego de ser elegido presidente Raúl Alfonsín (1983-1989), en la primera semana de su legislatura, realizó la derogación de la Ley de Auto-amnistía sancionada por las Fuerzas Armadas ${ }^{7}$. La publicación expuso de manera fehaciente, la existencia de un plan sistemático de represión basado fundamentalmente en la desaparición de personas.

En consecuencia, la documentación que recopiló la Comisión se transformó en la principal prueba para llevar adelante el juicio contra los militares. Así también, el trabajo realizado por la CONADEP, se transformó en "modelo y ejemplo inaugural de las Comisiones de Verdad que se establecieron en varios países latinoamericanos y fuera del continente" (Águila;

\footnotetext{
A través del Decreto 187 del 15 de diciembre de 1983, la CONADEP, tuvo como objetivo recopilar información de los diferentes delitos de violación de derechos humanos, entre los que se contaba la desaparición de personas entre 1976 y 1983, a través de los testimonios de los familiares de desaparecidos y sobrevivientes de los centros clandestinos de detención. La información recabada se publicó en el Informe Nunca más, conocido también como Informe Sábato.
} 
Luciani 2009:145). ${ }^{8}$ Se observa en este caso, que las acciones realizadas en los primeros años de la transición en Argentina, destinadas a resolver el problema de las violaciones de derechos humanos perpetradas durante la dictadura, señalan a este país como un caso emblemático en el contexto latinoamericano, debido tanto a la creación de la Comisión de Verdad como al juicio a las Fuerzas Armadas. Desde el punto de vista legal, se transforma en un precedente, como lo explica el destacado jurista Juan Méndez:

Los llamados 'juicios por la verdad', tal como llegó a conocerlos, fueron una innovación en la justicia argentina y posiblemente en el resto de las Américas. Difieren de los juicios penales ordinarios en cuanto la acción judicial se limita de manera expresa a una tarea de investigación y documentación, sin que exista la posibilidad de procesamiento o castigo. Estos juicios se basan en el derecho (tanto de los familiares como de la sociedad en su conjunto) a conocer la verdad, así como el derecho de los familiares de las víctimas a hacer el duelo por sus muertos y enterrarlos (Méndez 2007: 14).

El juicio de las Juntas militares se efectuó entre abril y diciembre de 1985. Fue conocido como el 'Juicio del Siglo' y afectó a nueve de los líderes de las juntas militares que gobernaron el país entre 1976 y 1983. Se trataron 281 casos, de los 709 originalmente ofrecidos por el fiscal, y declararon más de 800 personas. Las historiadoras Gabriela Águila y Laura Luciani, señalan que la única experiencia anterior en esta materia, fueron los Juicios de Núremberg.

En el país del Cono Sur, este Juicio tuvo un impacto a gran escala. En el ámbito social, permitió conocer nuevos elementos para

Respecto del Juicio a las Juntas Militares, véase Acuña, C., "Lo que el Juicio nos dejó", en Revista Puentes, n 2, La Plata, 2000. Cañón, H., "Un antes y un después", en Revista Puentes, n 3, La Plata, 2001. explicar el pasado mediato, pero sobre todo, estableció como prioridad condenar los crímenes de lesa humanidad. En el plano político, y de acuerdo a lo dictaminado por la Corte de Justicia, quedó la posibilidad de abrir nuevas medidas penales para militares de rangos inferiores. Sin embargo, en la década de los noventa, se llevaron a cabo los llamados 'perdones presidenciales', donde quedaron en libertad muchos de los inculpados, así como otros tantos que habían sido juzgados por tribunales menores producto de acusaciones particulares. Pese a ello, para el historiador argentino Luis Alberto Romero, la importancia de este juicio radica en que estableció:

(...) judicialmente que la dictadura constituyó un estado criminal, [y] se convirtió en un hito: juzgar y castigar a los culpables principales constituyó un hecho excepcional, en América Latina y en el mundo (Romero 2007: 115).

Así también, el título Nunca Más, se extendió a otras demandas vinculadas a los derechos humanos. Por consiguiente, el caso de Argentina, es el reflejo fehaciente de un proceso que se extendió por toda América Latina, alcanzando América Central y el Caribe, aunque en esta región en particular, la justicia política ha tenido menos oportunidades, aunque se evidencian esfuerzos como en los casos de Honduras, Nicaragua y el Salvador, pero debido a la problemática situación política esto ha sido mucho más difícil.

En consecuencia, qué hacer con el legado de violaciones de derechos humanos, es un problema que ha generado importantes debates dentro de las jóvenes democracias, puesto que en muchos casos, lo que se esperaba era una ruptura total con el régimen anterior. No obstante, debían dirimir en un contexto social y político altamente complejo, ya que por un lado 
se debía considerar las legítimas demandas de verdad y justicia, y por otro, dar estabilidad al nuevo gobierno. En estas experiencias, se observa que desde sectores partidarios de los regímenes salientes, se impugnaba la búsqueda de verdad y justicia, argumentando que estas acciones llevarían a desestabilizar la paz y el frágil orden alcanzado. Se argumentaba que el recuerdo de la violencia que había experimentado la sociedad era latente.

Si bien la experiencia argentina sentó un precedente, se observan otros esfuerzos por parte de las autoridades democráticas de realizar juicios. Es el caso de Bolivia, que entre 1986 y 1993, inició juicios de forma oficial. Sin embargo, se logró dictaminar fallos sólo a los máximos líderes del cruento período de García Meza (1981-1982). Tras un proceso que llevó siete años, García Meza fue por fin encarcelado en 1995 junto con todos los ministros de la época; once agentes paramilitares y el antiguo jefe de las Fuerzas Aéreas. Estos casos, representan un gran esfuerzo por parte de los gobiernos democráticos de sancionar por primera vez y de forma legal a los responsables de las violaciones de derechos humanos.

Si bien, gran parte de las condenas -como era de esperar-, no se llegaron a cumplir, si se advierte un esfuerzo estatal por hacer justicia. En otros casos, en los que no existieron procesos judiciales oficiales, se iniciaron demandas a los responsables de forma individual, y a través de organismos de derechos humanos. En algunos de ellos se realizaron condenas, como es el caso de Argentina, Chile, Ecuador y Paraguay. Sin embargo, la impunidad sobre gran parte de los represores, se manifestó a través de leyes de amnistía que eliminaron o bien, restringieron la esfera de acusaciones. Los casos de Brasil
(1979), Chile (1978) y Uruguay (1989) son representativos de estas cuestiones ${ }^{9}$.

En América Central los procesos relacionados a la justicia política, no tuvieron tantas oportunidades de concretarse, debido a la complejidad de sus conflictos internos, en los que se cruzan cuestiones de tipo étnicas, con aquellas vinculadas a la guerrilla y grupos paramilitares. Lo que se observa, es que los esfuerzos se han centrado más indagar sobre lo sucedido a las víctimas, que en juzgar a los responsables. Uno de estos casos es el de Guatemala cuyo proceso de transición democrática fue el resultado de extensas negociaciones de paz supervisados por Naciones Unidas.

El conflicto en Guatemala de más de tres décadas, tenía a su población sumida en el miedo, la muerte y la desaparición de personas. El historiador guatemalteco Arturo Taracena, señala que la creación de la Comisión de Verdad, fue el propósito de "uno de los acuerdos firmados entre el gobierno y la Unidad Revolucionaria Nacional Guatemalteca (URNG) entre 1994 y 1996" (Taracena 2007: 2), sin embargo, recién en 1997 logró crearse la Comisión de Esclarecimiento Histórico de Guatemala $(\mathrm{CEH})^{10}$, como resultado del Acuerdo de Oslo, el 23 de

Nos referimos a las leyes de Amnistía que se aplicaron en Brasil, Chile y Uruguay, estas fueron: Brasil, Decreto Ley $n^{\circ} 6.683$ del 22 de agosto de 1979; Chile, Decreto Ley $n^{\circ} 2.191$, que concede amnistía general, bajo las circunstancias que indica, por los delitos que señala, del 18 de abril de 1978. Diario Oficial del 19 de abril de 1978. República Oriental del Uruguay, Ley $n^{\circ} 15.737$, que aprueba la Ley de Amnistía, del 08 de marzo de 1985

10 El «Acuerdo de Oslo, 23 de junio de 1994», firmado entre el Gobierno de Guatemala y la Guerrilla, con el auspicio de la ONU. Véase Simon, J. M., "La Comisión para el Esclarecimiento Histórico, verdad y justicia en Guatemala. Disponible en, <http:// www.ejournal.unam.mx/bmd/bolmex106/BMD10606.pdf>. (Consultado en noviembre de 2016). 
junio de 1994. Su objetivo fue "esclarecer con toda objetividad, equidad e imparcialidad las violaciones a los derechos humanos y los hechos de violencia que han causado sufrimientos a la población guatemalteca, vinculados con el enfrentamiento armado" (CEH 1999 :11). Como otras comisiones, no tuvo atribuciones judiciales, sino que se centró en dar a conocer "la historia de lo acontecido durante más de tres décadas de guerra fratricida" (CEH 1999: $11)^{11}$. Entre las recomendaciones que realizó la Comisión, estaban los cambios legales e institucionales, así como una depuración militar, junto a la investigación judicial. Se sugirió también realizar exhumaciones de cadáveres, y otorgar una reparación a las víctimas. A pesar de estos hechos que demuestran una vez más la crudeza de una realidad muchas veces silenciada, se observa que tanto las demandas como la institucionalización de verdad y justicia, no fueron fáciles. En este caso, si bien la intervención de la ONU permitió que se creara la Comisión, no pudo impedir, que en 1996 se promulgara la Ley de Reconciliación Nacional ${ }^{12}$, que excluyó los crímenes contra la humanidad y el genocidio, entre otros. Esta situación llevó a que Amnistía Internacional, en 1999 expusiera públicamente sus reservas frente a esta ley indicando que dejaba "abiertas varias puertas a la impunidad"13.

11 Dentro de los 152 puntos que conformaron sus conclusiones, se identificaron las raíces históricas de la violencia, se publicó el número de desaparecidos y muertos. Se identificó el genocidio contra el pueblo maya. $Y$ las responsabilidades que recayeron tanto al Estado como a la guerrilla.

12 Guatemala, Decreto Ley $\mathrm{n}^{\circ}$ 145, que crea la Ley de Reconciliación Nacional, del 27 de diciembre de 1996, de 27 de diciembre de 1996. Disponible en, <http://www.acnur.org/biblioteca/pdf/0148. pdf?view=1>. (Consultado en noviembre de 2016).

13 Véase texto completo publicado por Amnistía Internacional. Disponible en, <http://www.es.amnesty.org/com/1999/com_02dic99. htm>. (Consultado en noviembre de 2016).
A pesar de la existencia de trabas y en algunos retrocesos en los procesos de búsqueda de la verdad y la justicia, debido a que las sanciones judiciales a los responsables de los crímenes no se cumplen totalmente, ya sea porque se rebajan las condenas, o bien se amnistían, generando malestar en la sociedad civil. Lo cierto es que las Comisiones de Verdad, adquieren un carácter fundacional. En este contexto, Arturo Taracena que fue parte de la Comisión de Esclarecimiento Histórico (CEH), explica que:

Cabe ubicar esta iniciativa entre los intentos oficiales por enfrentar el conocimiento del pasado en el istmo, en los últimos cincuenta años y la aplicación de medidas de justicia y reparación, con el fin declarado de contribuir a la reconciliación nacional y a la transición democrática (Taracena 2007: 3).

Como hemos analizado, las transiciones políticas son complejas, ya que responden a la heterogeneidad de sus procesos históricos. Se observan elementos comunes como la experiencia de la violencia y la búsqueda de la verdad y justicia. Sin embargo, en América Central es posible identificar diferencias en estos procesos. Por un lado, la injerencia y el rol de actores internacionales que influyeron de manera efectiva en estos procesos. En este caso, la Organización de Naciones Unidas (ONU), que también colaboró en la experiencia transicional de El Salvador. Por otro lado, se advierte que el tipo de negociación política, tanto para revelar la verdad, como para la elección de gobiernos democráticos, no fue simultánea, sino que fue el resultado final de conflictos armados, cuestión que no ocurrió en los países del Cono Sur. Estos elementos de análisis, ponen de manifiesto que las diferencias entre las formas y resultados de las políticas de verdad y justicia adoptadas por los Estados, tienen directa relación con el contexto social y político en el que se desarrollan. 


\section{Las huellas de las violencias cometidas}

Los temas vinculados a sociedades que padecen de un pasado difícil y traumático, han sido abordados con diferentes énfasis desde la filosofía por Michel De Certeau, y sus reflexiones respecto de aquello que se puede 'nombrar' (De Certeau 2006), junto a las aportaciones de Hannah Arendt y Slavoj Zizek sobre las 'herramientas' necesarias para ejecutar la violencia (Arendt 2008; Zizek 2009). Los enfoques venidos de la sociología a través de las investigaciones de Elizabeth Jelin, y sus reflexiones sobre 'los lugares, las fechas in-felices, las marcas y los emprendedores de memoria' (Jelin 2002; Jelin y Da Silva 2002; Jelin y Langland 2003; Jelin y Longoni 2005) que sumados a investigaciones históricas, como las de Pierre Nora, quien señala respecto a los 'lugares de memoria', no sólo como aquello tangible, sino como repositorio también de lo inmaterial y simbólico (Nora 1992; 2009), se transforman en elementos que otorgan un panorama de reflexión teórico-metodológico que permite identificar la matriz conceptual desde la que se desplazan los análisis sobre este tipo de pasados.

\subsection{Las memorias fracturadas}

Las cercanías a los temas de memoria e historia, han presentado encuentros y lejanías que bien vale analizar. Las tensiones han sido variadas y desde diversos escenarios, en donde la historia ha podido encontrar en el transcurso del siglo XX varios 'espejos' sobre los cuales replantear la óptica desde donde analiza su objeto de estudio. Desde esta perspectiva, podemos explorar las múltiples posibilidades que ofrece la historia para la comprensión de nuestros pasados, aproximándonos en esta línea a lo expuesto por Joseph Fontana, esto es, comprender la historia como transformación social (Fontana 2004), puesto que si las sociedades conocen su pasado pueden elaborar un relato que favorezca aprendizajes que eviten situaciones de violencia política ejercidas por el Estado.

En este caso, interesa la relación que existe entre memoria y recuerdo, en cierto tipo de sociedades donde se advierte un proceso de reelaboración del pasado reciente, considerando en ello, políticas de memoria y de olvido.

Las investigaciones realizadas en torno a la relación del recuerdo han sido profusas, y las aportaciones de la sociología han sido claves, con trabajos fundacionales como los de Norbert Elías, Marcel Mauss y Maurice Halbwachs, son un precedente insoslayable para ingresar al estudio de estos temas (Elías 1989; Mauss 1979; Halbwachs 2004). Tal vez, podríamos señalar que desde la historia George Duby y Michelle Perrot, al indagar en aquello de 'lo privado', se acercaron a estas problemáticas, a través de las prácticas cotidianas, pero de manera tangencial (Duby y Perrot 2001). Sin duda, la complejidad -parafraseando a Edgar Morín- al momento de abordar los temas sobre historia, memoria y olvido es una constante (Morín 1990). Sin embargo, desobedecemos al olvido, por cuanto buceamos en las fronteras de aquello que resulta 'difícil' de narrar y de nombrar, ya que está referido al estudio de los efectos dejados por las violencias políticas.

Resulta interesante indagar en las narrativas que desde la historia se elaboran para abordar los trabajos de memoria. Como se ha señalado, la historia del tiempo presente, considera a la memoria como una fuente para el análisis de estos procesos, debido sobre todo a la cercanía 
de los hechos, donde coexisten testigos, huellas, víctimas y victimarios.

Se advierte una mayor profusión los temas vinculados a un tipo de memoria histórica, sobre todo en el siglo XX, cuya característica fundamental ha sido la catástrofe humana, representada por la violencia. De ahí que el concepto de memoria, tenga una mayor asociación con las situaciones traumáticas, ya que la impronta vivida ha sido mayoritariamente de guerras, genocidios, dictaduras, destrucción masiva del medioambiente, entre otros. En definitiva, a una aceleración de los procesos históricos y no a una ruptura con el pasado.

Es evidente que la memoria y los recuerdos construyen nuestro pasado, adquiriendo la forma de segmentos o capas que se depositan en nuestro imaginario tornándose dinámicos. Esta representación adquiere mayor connotación con el acto de habla, puesto que es "en el lenguaje, el destino de todos los términos que realmente tienen vida" (Bloch 2001: 53). Y si quisiéramos darles consistencia a estos enunciados, baste sólo indicar a los sobrevivientes de los campos de concentración en Europa y las víctimas de tortura y prisión política, para los casos de América Latina. Si, como hemos enunciado, la tragedia se ha hecho evidente en el pasado siglo, sobre todo por la proximidad del relato y la impronta de su narrativa, es en este escenario, paisaje de la historia, donde la memoria, como objeto de la historia $-y$, por tanto, fuente-, se ha materializado por excelencia. De allí que interese examinar la significación que adquiere para comprender las proximidades históricas.

Por otra parte, es importante considerar que el olvido es el reverso indiscutible de la memoria. Historiográficamente ha sido abordado de forma tangencial, sobre todo a través del tratamiento de los archivos, cuando se les ha interrogado con nuevas preguntas, que, si bien dan cuenta de la inclusión de una mayor gama de categorías de análisis, permiten también diagnosticar las ausencias, vacíos y huecos existentes sobre los pasados. Si bien existe una amplia gama de tipos y formas de olvidos, nos centramos en aquellos olvidos colectivos, que están imbuidos de olvidos individuales, ampliamente investigados por la psicología. Por tanto, cuando nos referimos aquí al tratamiento del olvido, la reflexión es desde lo colectivo, proyectándolo en aquellas sociedades que han experimentado las violencias de Estado.

Desde las diversas áreas del conocimiento, se han desarrollado importantes reflexiones vinculadas al olvido, diagnosticando sus matices y resistencias, las que van desde aquellos que se instalan de forma institucional, y que considera dentro de sus espacios de acción, sólo aquellos vinculados a la polis, y cuyas categorías se encuentran ligadas a la conformación del Estado-Nación, siguiendo la idea de Benedict Anderson de comunidades imaginadas (Anderson 1993). Estos estudios han indagado en aquellas narraciones que construyen los estados, donde se evidencian olvidos, silencios y huecos institucionalizados en pos de una 'memoria patria' como lo denominaba Steve Stern (Stern 2009).

La complejidad del análisis se advierte cuando ingresamos a estos estadios de la reflexión, esto es, que las generaciones, sólo pueden recordar aquello que han vivido, de lo que han sido parte. La gran mayoría de los autores vinculados a estos temas advierten que cuando se dice que un pueblo 'recuerda', en el fondo lo que se está planteando es que un tipo de 
pasado fue transmitido de manera activa a las generaciones contemporáneas, a través de lo que Yosef $\mathrm{H}$. Yerushalmi ha denominado "canales y receptáculos de la memoria" (Yerushalmi 1998: 17) y que Pierre Nora llama los lugares de memoria (Nora 1998), y que es resignificado otorgándole un sentido propio. A los responsables de este trabajo de memoria, es lo que Elizabeth Jelin, ha denominado 'emprendedores de memoria'.

La experiencia humana incorpora vivencias propias, pero también las de otros que le han sido transmitidas. El pasado, entonces, puede condensarse o expandirse, según cómo esas experiencias pasadas sean incorporadas (Jelin 2002: 34).

Esta es una cuestión clave, porque de lo que se trata es de indagar en aquellas grietas, fracturas y huellas dejadas por este tipo de memorias. En este contexto Jelin, identifica tres ámbitos de análisis, el primero referido a quién es el que rememora y olvida. Por otro lado, a los contenidos, es decir, vinculado a qué se recuerda y qué se olvida. $Y$ un tercer ámbito, se refiere cómo y cuándo se recuerda y olvida. En este aspecto se advierte que esta última pregunta, surge debido a la ansiedad y angustia que genera la posibilidad del olvido. Tanto en el plano individual como social, las preocupaciones frente al olvido son similares. Si bien tanto las capacidades de recordar y olvidar son singulares, no es menos cierto que no ocurren en individuos aislados, sino insertos en redes de relaciones sociales, en grupos, instituciones y culturas.

En este aspecto, son los acontecimientos traumáticos los que conllevan grietas en la capacidad narrativa, generando huecos en la memoria, y que corresponderían a aquello inasequible, y que no permite dar un sentido al acontecimiento pasado, aquello que imposibilita incorporarlo narrativamente, pero que a su vez coexiste. La socióloga sostiene que es precisamente:

(...) su presencia persistente y su manifestación en síntomas, lo que indica la presencia de lo traumático. En este nivel, el olvido no es ausencia o vacío. Es la presencia de esa ausencia, la representación de algo que estaba y ya no está, borrada, silenciada o negada (Jelin 2002: 28).

$Y$ es que es en aquellas memorias narrativas donde se pueden encontrar los sentidos del pasado, así como las 'heridas de la memoria, más que las memorias heridas'. "En todo esto, el olvido y el silencio ocupan un lugar central. Toda narrativa del pasado implica una selección (Jelin 2002: 29). Seguimos aquí a Paul Ricoeur, quien identifica tres niveles de profundidad respecto al olvido. El primer olvido, profundo e inexorable, se podría llamar también 'definitivo', y que "responde a la borradura de hechos y procesos del pasado, producidos en el propio devenir histórico" (Ricoeur 1999: 16). Dentro de este marco de análisis, existen aquellos pasados que parecían olvidados de forma definitiva, pero que vuelven a aparecer cobrando vigencia debido a "cambios en los marcos culturales y sociales que impulsan a revisar y dar nuevo sentido a huellas y restos, a los que no se les había dado significado durante décadas o siglos" (Jelin 2002: 29).

Este es un tema de gran alcance, ya que toda política de conservación y de memoria, al seleccionar huellas para preservar, conservar o rememorar, tiene implícita una voluntad de olvido. Varios son los autores que nos recuerdan la responsabilidad de quienes investigan estos temas, cuando eligen qué contar, qué representar o qué escribir en un relato. De lo anterior, podemos deducir que lo 
que efectivamente deja el pasado son 'huellas' ya sea simbólicas, materiales, psíquicas, todas las que necesitan ser evocadas y ubicadas en un marco que les otorgue sentido.

En este aspecto Paul Ricoeur, expone que nos encontramos frente a un segundo tipo de olvido, "(...) que no consiste en la pérdida de las huellas o en la destrucción o disolución de los restos del pasado, sino en la aparición de impedimentos para acceder a nuestros recuerdos" (Ricoeur 1999:105). Desafío, que en palabras de Ricoeur, se trata de "atravesar el muro que nos separa de esas huellas" (Ricoeur 1999:105). El problema que subyace no es la falta de huellas sobre ese pasado, sino más bien, los dispositivos de represión instalados desde diversos escenarios, que evitan llegar a ese tipo de huellas y por tanto de elaboración de esas memorias. Lo contrario a ello, es lo que Andreas Huyssen, denominan como "obsesión de la memoria", o "abusos de la memoria" (Todorov 2008). Por su parte, Ricoeur identifica un tercer tipo de olvido, que denomina 'evasivo', y que es aquel que se elude para evitar el sufrimiento, en un intento de no recordar aquello que puede herir. Este tipo de olvido se puede transformar en un olvido 'activo', situación que tiene lugar sobre todo en

(...) el plano de la historia y de las grandes catástrofes históricas, en épocas de grandes pérdidas o de grandes masacres, como sucedió en Europa, por ejemplo, en tiempos de la Shoah (Semprún 1997: 31).

Desde esta óptica, lo contrapuesto del olvido sería el silencio, existiendo en esta óptica silencios impuestos por temor a la represión de diversos tipos de regímenes de corte dictatorial, como por ejemplo en el caso de la España franquista y de la URSS bajo Stalin. "En estos casos, sobreviven recuerdos dolorosos que 'esperan el momento propicio para ser expresados'” (Pollak 1989: 5).

Así también se encuentra la decisión de guardar silencio, de no querer narrar ni transmitir nada, de esconder, almacenar los vestigios y rastros en zonas recónditas, para cuidar a los otros, como una forma de no querer transmitir sufrimientos. Pero "hay otra lógica en el silencio. Para relatar sufrimientos, es necesario encontrar el otro lado la voluntad de escuchar" (Jelin 2002: 31). En relación a esta afirmación, observamos que efectivamente, existen ocasiones, como las transiciones políticas, que el afán de reconstruir lo vivido, se torna paradójico, ya que aparecen las disputas de la memoria, donde se vehicula a su vez, los horrores de ese pasado. Por último, se encontraría el olvido liberador, que libera de la carga del pasado para así poder mirar al futuro. Siguiendo a Ricoeur, Jelin explicita que:

Es el olvido 'necesario' en la vida individual. Para las comunidades y grupos, el origen este planteamiento está en Nietzsche, al condenar la fiebre histórica y al reclamar un olvido que permita vivir, que permita ver las cosas $\sin$ la carga pesada de la historia (Jelin 2002: 31).

En este punto del análisis, nos encontramos con los problemas de los abusos de la memoria que se pueden presentar al mismo tiempo que los olvidos. Estas problemáticas se pueden abordar de mejor forma a través adecuadas políticas de gestión del pasado, aunque bien es cierto, nunca está exento de caer en la administración de ese pasado.

\section{Reflexiones posibles}

El análisis de las sociedades en que vivimos, presenta un importante desafío que, desde la perspectiva de la historia del tiempo presente, 
impulsa a indagar en aquellos pasados de los que somos coetáneos, accediendo desde el presente al pasado, comprendiendo las dinámicas históricas de los procesos sociales permitiendo entre otros, la reflexión cotidiana de problemáticas que enlutan el acontecer de las sociedades.

La reconstrucción del pasado es un hecho que se vuelve fundamental cuando se reflexiona sobre aquellas sociedades que han experimentado situaciones de violencia de Estado, ya que se une al trabajo investigativo de fuentes y archivos con un fin mayor, que está ligado a los Nunca Más. Desde nuestro oficio, el desafío se instala es interpelar las fuentes, por más próximas que se encuentren, y con un método de investigación científica, abordarlas intentado dar cuenta de las evidencias que sostienen la magnitud de los hechos. En este contexto, las disputas sobre el pasado reciente en estas sociedades es un hecho en el que confluyen las voces de las víctimas que claman justicia y muy a menudo el silencio de los que antes mantuvieron el poder político. Entre unos y otros existe un abismo inconmensurable: la violencia de Estado que se aplicó dentro del territorio nacional, los miles de víctimas, los detenidos, torturados, ejecutados políticos y desaparecidos, es el panorama al que se ven enfrentados los gobiernos de procesos de transición política no sólo en la región Latinoamericana.

A través del estudio de la represión política se accede a la memoria histórica de este pasado, cuya característica central es la sistemática violación de derechos humanos. La historia de nuestro tiempo, tiene matices, y uno de ellos está relacionado con las profundas huellas que han dejado las violencias políticas. Cómo recomponer ese tiempo, cómo aprehenderlo históricamente. Por ejemplo, cómo las sociedades han 'nombrado' el padecimiento sufrido por los cientos de víctimas. Es decir, cómo desde nuestros ámbitos profesionales examinamos problemáticas que han lacerado profundamente a las sociedades. Sin duda, la complejidad es la mayor fortaleza porque lleva, a indagar en otros ámbitos del conocimiento, acercándonos al reconocimiento de un pasado que no pasa, que emerge por los recovecos de su propia historia, y esto se debe que las sociedades son el reflejo de su pasado. Por ello es significativo que se generen espacios para saber lo sucedido de un pasado que sigue siendo incómodo para algunos, y necesario para otros, un pasado a veces lleno de silencios y otros sobrepoblado de detalles que se transforman en pistas que permiten dar con el paradero de alguna víctima, o bien, que permite el reconocimiento de aquellos lugares donde se perpetraron las violencias. Es en estos temas donde instalamos nuestras interrogantes.

En consecuencia, reflexionar sobre historia y memoria desde el Cono Sur, lleva también a interrogarnos sobre los soportes teóricos que permiten analizar estas problemáticas, dotando de contenido un tiempo y espacio que ha tenido la impronta de las violencias de Estado. 


\section{Bibliografía}

Águila, G., Luciani, L. 2009. "Argentina: Crímenes de Estado y Memoria". Los crímenes de Estado y su gestión. Dos experiencias postraumáticas y una aproximación a la justicia penal internacional. García, A. (ed.). Madrid: Catarata.

Aguilar, P. 2002. Políticas de la Memoria y Memorias de la Política. Madrid: Alianza Editorial.

Anderson, B. 1993. Comunidades Imaginadas. Reflexiones sobre el origen y la difusión del nacionalismo. México: F. C. E.

Arendt, H. 2008. Sobre la Violencia. Madrid: Alianza Editorial.

Aróstegui, J. 1998. "Tiempo contemporáneo y tiempo presente. Una reconsideración necesaria". Historia del tiempo presente. Teoría y Metodología. Díaz Barrado, M. (coord.). Extremadura: Universidad de Extremadura.

Aróstegui, J. 2004. La Historia vivida. Sobre la historia del presente. Madrid: Alianza Editorial.

Barahona, A., Aguilar, P. y González, C. (ed.) 2002. Las políticas hacia el pasado. Juicios, depuraciones, perdón y olvido en las nuevas democracias. Madrid: Istmo.

Bédarida, F. 1998. "Definición, método y práctica de la Historia del tiempo presente". Cuadernos de Historia Contemporánea. $N^{\circ}$ 20. Madrid: UCM

Bloch, M. 2001. Apología para la historia o el oficio del historiador. México: FCE.

Bloch, M. 2002. La extraña derrota. Barcelona: Crítica, 2002. ( $1^{\circ}$ edición 1944).

Comisión para el Esclarecimiento Histórico.1999. Guatemala, Memoria del Silencio. Conclusiones y Recomendaciones. Capítulo IV. Guatemala: UNOPS.

De Certeau M. 2006. La escritura de la Historia. México: Universidad lberoamericana. ( $2^{\mathrm{a}}$ reimpresión en español).

Elías, N. 1989. El proceso de la civilización investigaciones sociogenéticas y Psicogenéticas. México: F. C. E. Crítica.

Fontana, J. (ed.) 2004. Historia y proyecto social. Barcelona:

Foucault, M. 1986. La arqueología del saber. México: Siglo XXI. González, A. 2009. Políticas archivísticas para la defensa de los derechos humanos. Paris: Consejo Internacional de Archivos ICA.

Halbwachs, M. 2004. Los Marcos Sociales de la Memoria. Barcelona: Anthropos.

Halbwachs, M. 2004. La Memoria Colectiva. Zaragoza: Prensas Universitarias de Zaragoza.

Huntington, S. 1994. La tercera ola de la democratización a finales del siglo XX. Barcelona: Paidós.

Informe de la Comisión Nacional sobre Desaparición de Personas. 1984. Nunca Más. Buenos Aires: Eudeba.

Jelin, E. 2002. Los trabajos de la memoria. Colección Memorias de Represión. Madrid: Siglo XXI.

Jelin, E. (comp.) 2002. Las conmemoraciones: Las disputas en las fechas "in-felices". Madrid: Siglo XXI.

Jelin, E., y Da Silva, L. (comps.)2002. Los archivos de la
Represión: Documentos, Memoria y verdad. Madrid: Siglo XXI. Jelin E., y Langland, V. (comps.) 2003. Monumentos, memoriales y marcas territoriales. Colección Memorias de Represión. Madrid: Siglo Veintiuno de España Editores.

Jiménez, J. C. 2009. España y Portugal en transición. Los caminos a la democracia en la Península Ibérica. Madrid: Sílex Barral.

Le Breton, D. 1999. Antropología del dolor. Barcelona: Editorial Seix Barral.

Mauss, M. 1991. Sociología y Antropología. Madrid: Tecnos. $\left(1^{\text {a }}\right.$ ed. 1979).

Méndez E. J. 2007. "El derecho humano a la verdad. Lecciones de las experiencias latinoamericanas de relato de la verdad". Historizar el pasado vivo en América Latina. Pérotin-Dumon, A. (Dir.). Santiago: UAH. Disponible en <http://etica.uahurtado. $\mathrm{cl} / \mathrm{historizarelpasadovivo/es}$ contenido.php>. (Consultado en octubre de 2016).

Morin, E. 2009. Introducción al pensamiento complejo. Barcelona: Gedisa.

Nora, P. 1992. Les Lieux de mémoire III. Paris: Gallimard. LOM.

Nora, P. 2009. Pierre Nora en Les lieux de mémoire. Santiago:

O' Donnell, G., y Schmitter, P. 1988. Transiciones desde un gobierno autoritario. Conclusiones tentativas sobre las democracias inciertas. Vol. IV. Buenos Aires: Paidós.

Romero, L. A. 2007. "La violencia en la historia argentina reciente: un estado de la cuestión". Historizar el pasado vivo en América Latina. Pérotin-Dumon, A. (Dir.). Santiago: UAH.

Ricoeur, P. 2003. La Memoria, la Historia y el Olvido. Madrid: Trotta.

Ricoeur, P. 1999. La lectura del tiempo pasado: Memoria y olvido. Madrid: Arrecife-UAM.

Semprún, J. 1997. La escritura o la vida. Barcelona: Tusquets.

Soto, A. 2009. "La transición a la democracia en el sur de Europa. La historia como instrumento para su comparación". Revista de Estudios Internacionales $N^{\circ} 162$. Santiago: Universidad de Chile.

Stern, S. 2009. Recordando el Chile de Pinochet en vísperas de Londres 1998. Santiago: UDP.

Taracena, A. 2007. "La experiencia de un historiador en la Comisión de Esclarecimiento Histórico de Guatemala". Historizar el pasado vivo en América Latina. Pérotin-Dumon, A. (Dir.). Santiago: UAH. Todorov, T. 2008. Los abusos de la memoria. Barcelona: Paidós.

Trebitsch, M. 1998. "El acontecimiento, clave para el análisis del tiempo presente". Cuadernos de Historia Contemporánea. N'20 Madrid: UCM.

Zizek, S. 2009. Sobre la violencia. Seis reflexiones marginales, Buenos Aires: Paidós.

Yerushalmi, Y. (et. al.) 1998. Usos del Olvido. Buenos Aires: Nueva Visión. 